\begin{abstract}
Iranica
Abstracta Iranica Revue bibliographique pour le domaine irano-aryen

Volume 42-43 | 2021

Comptes rendus des publications de 2019-2020

\section{Bastian Still, Rieneke Sonnevelt. “On Sippar's Quay: Cuneiform Tablets with Aramaic Inscriptions from the Böhl Collection in Leiden"}

Louise Quillien

\author{
(2) OpenEdition \\ Journals \\ Édition électronique \\ URL : https://journals.openedition.org/abstractairanica/52783 \\ DOI : 10.4000/abstractairanica.52783 \\ ISSN : 1961-960X \\ Éditeur : \\ CNRS (UMR 7528 Mondes iraniens et indiens), Éditions de l'IFRI
}

Référence électronique

Louise Quillien, « Bastian Still, Rieneke Sonnevelt. “On Sippar's Quay: Cuneiform Tablets with Aramaic Inscriptions from the Böhl Collection in Leiden" », Abstracta Iranica [En ligne], Volume 42-43 | 2021, document 42, mis en ligne le 30 juillet 2021, consulté le 14 décembre 2022. URL : http:// journals.openedition.org/abstractairanica/52783; DOI : https://doi.org/10.4000/abstractairanica. 52783

Ce document a été généré automatiquement le 14 décembre 2022.

Tous droits réservés 


\title{
Bastian Still, Rieneke Sonnevelt. “On Sippar's Quay: Cuneiform Tablets with Aramaic Inscriptions from the Böhl Collection in Leiden"
}

\author{
Louise Quillien
}

\section{RÉFÉRENCE}

Bastian Still, Rieneke Sonnevelt. “On Sippar's Quay: Cuneiform Tablets with Aramaic Inscriptions from the Böhl Collection in Leiden”, Zeitschrift für Assyriologie und vorderasiatische Archäologie 2020, 110(1), p. 94-110.

1 Les auteurs présentent dans cet article l'édition de trois tablettes cunéiformes conservées dans la Collection Böhl (Leyde, Pays-Bas). Ces documents dont datés des règnes de Darius I et de Xerxès I (494-485 av. J.-C.) et proviennent de la ville de Sippar. Il s'agit des trois seules tablettes néo-babyloniennes de la Collection Böhl comportant une épigraphe araméenne. Elles concernent toutes les trois les activités de marchands du port ( $k \bar{a} r u)$ de Sippar et leur implication dans le commerce de la bière et peut-être des textiles.

2 Le premier texte est une reconnaissance de dette pour de l'argent appartenant à Dummuqu/Bēlšunu, le deuxième est un contrat pour le lavage du linge de ce même Dummuqu, qui doit être réalisé par un esclave au nom égyptien, et le troisième est une reconnaissance de dette pour des jarres destinées au stockage et au transport de la bière, appartenant à Adad-zēru-iddin/Ișșūr. Les auteurs montrent que ces textes proviennent du même contexte archivistique, appelé le groupe "Maštuk», et qu'il existe des liens indirects entre les protagonistes de ces documents et les autres familles d'entrepreneurs actifs sur le quai de Sippar, notamment celles de Marduk-rēmanni/ ȘāHit-ginê (A) et de leurs cousins ȘāHुit-ginê (B). 
3 Ces trois textes témoignent, selon les auteurs, d'un usage répandu de l'araméen dans le milieu des marchands du port de Sippar, à l'époque de la domination achéménide. Le texte $n^{\circ} 1$ présente une différence intéressante dans les pratiques d'écriture des deux langues : le texte cunéiforme nomme le débiteur par le nom de son père, Bēl-iddin fils de Nabû-ẹtir-napšāti, tandis que l'épigraphe araméenne mentionne uniquement le nom de sa mère, ${ }^{\mathrm{f}}$ Amtia. A travers ces textes, il apparaît que certaines personnes comme les femmes, les individus d'origine étrangère à la ville et les esclaves, alors qu'elles sont peu mentionnées comme acteurs économiques dans les archives des temples, tiennent une place active dans le milieu marchand du port de Sippar.

\section{AUTEURS}

\section{LOUISE QUILLIEN}

CNRS, UMR 7041, Arscan 